\title{
Survey and significance of filamentous fungi from tap water
}

\author{
Ana B. Gonçalves, R. Russell M. Paterson, Nelson Lima* \\ Centro de Engenharia Biológica, Micoteca da Universidade do Minho, Campus de Gualtar, 4710-057 Braga, Portugal
}

Received 19 May 2005; received in revised form 13 December 2005; accepted 28 December 2005

\begin{abstract}
Fungi in drinking water are involved in the production of tastes and odours in water. Health problems are possible, originating from mycotoxins, animal pathogens and allergies. This report concerns the surveillance of mesophilic fungi in tap water and assessment of their potential for causing problems. The methods for the determination of the filamentous fungi (ff) were filtering, swabbing and baiting. Tap water, half-strength corn meal, neopeptone-glucose rose Bengal aureomycin (NGRBA) and oomycete selective agars for the enumeration of colony forming units (cfu) were used. Samples were taken consecutively over 16 months. Filtration and NGRBA gave the highest ff counts. A total of 340 taxa were isolated. There appeared to be a negative correlation between bacterial and yeast $(\mathrm{b} / \mathrm{y})$ and $\mathrm{ff}$ counts. Highest counts were found in winter months for ff and in the warmer months for b/y. Penicillium (40.6\%) and Acremonium (38.8\%) were the most frequently isolated ff. There was a difference in the pattern of isolation of the key taxa with season: penicillia predominated in early summer and Acremonium in winter. P. expansum was isolated in high numbers in May 2004. This species is associated with the production of the mycotoxin patulin and the odour secondary metabolite geosmin. P. brevicompactum was detected throughout the sampling period and is known to produce the immunosuppressive drug mycophenolic acid. Acremonium is associated with ocentol production which is responsible for bad tastes and flavours. The remaining taxa were Phialophora sp. (4.1\%), Cladosporium sp. (3.5\%), Rhizopus stolonifer (2.9\%), Chaetomium sp. (0.6\%), Alternaria sp. (0.3\%), Aspergillus sp. (0.3\%), mycelia sterilia (2.6\%) and unidentified (6.2\%). It is emphasised that few Aspergillus and no Fusarium strains were isolated. Rhizopus stolonifer was obtained. However, none of the fungi isolated at mesophilic temperature used could be described as being involved with pathogenicity per se.
\end{abstract}

(C) 2006 Elsevier GmbH. All rights reserved.

Keywords: Fungi; Pathogenicity; Tap water; Penicillium expansum; P. brevicompactum; Acremonium

\section{Introduction}

Fungi are a ubiquitous and diverse group of eukaryotic organisms. They are accepted as a fifth kingdom comprising 70,000 named species with as many as 1.5 million species predicted (Hawksworth, 2004).

\footnotetext{
*Corresponding author. Tel.: + 351253604403 ; fax: +351253678986

E-mail address: nelson@iec.uminho.pt (N. Lima).
}

Sizes range from massive underground structures to microscopic single-celled yeasts. A large and familiar group grow by extending filaments to absorb nutrients and use sporing structures called conidiophores for dispersal: The spores are referred to as conidia and are produced by mitosis. These are generally the mitosporic fungi. They are associated intrinsically with water because they are omnipresent, so it is unsurprising that they may occasionally cause problems. Micoteca da Universidade do Minho is involved in an EU funded 
project concerning surveillance and control of microbiological stability in drinking distribution networks where identifying fungi and assessing their potential or emerging pathogenicity in tap water is one of a number of tasks. So what are the potential problems?

A clear and unambiguous statement as to the significance of fungi in drinking water is difficult to provide because there have been few systematic studies. Also, it is difficult to compare data between laboratories due to a (a) lack of standardised and (b) inadequate methodology. For example, colony-forming units (cfu) are employed universally. It is not know whether a colony is from a conidium, conidiophore, hyphae or other spores. The colony may have been derived from numerous units (e.g. a clump) rather than one. It is therefore relatively common for these data to be overinterpreted as to significance. However, potential problems are infections of animals (including humans), organoleptic, and mycotoxin production.

Mycotoxins are toxic metabolites produced by certain fungi and are often associated with food (CAST, 2003). Aflatoxins and Aspergillus flavus were detected from stored water (Paterson et al., 1997). However, whether the compounds were dissolved is debatable. Zearalenone-like substances were dissolved in the same water (Kelley et al., 2003). Some domestic tap water had only trace amounts of aflatoxin $B_{1}$ as reported in the same study. It is likely that such contamination will be minimal in normal domestic tap water. Problems will tend to increase if the water is stored (e.g. bottled water), or is evaporated as occurs for some food production. Another potential problem of which we are only just becoming aware, is the use of fungi or more likely, fungal toxins, as biological/chemical weapons which could be added to the water supply (Paterson and Lima, 2005). In this case, some knowledge of base line levels of fungi (and toxins) would be desirable.

Fungi in air and soil can reach high numbers and may enter water distributions from various locations, and vice versa. Furthermore, they can become established in many ways such as in sediments, plant debris, biofilms, etc. Kelley et al. (2003) wrote the most up-to-date and comprehensive report of fungi in distribution systems, and Göttlich et al. (2002) gave an important addition. It is reasonable to assume, a priori, that common fungi such as penicillia and aspergilli are likely to present in high numbers. Fusaria may be less likely as they are associated with plants. These three are also the fungi mostly associated with mycotoxin production. In terms of fungi in water distribution systems, it is apparent that previous studies did not identify to the species level, and genus names were the only information available. Nevertheless, Acremonium, Paecilomyces, Penicillium and Sporocybe predominated in chlorinated and unchlorinated systems (Kelley et al., 2003). In chlorinated systems fed from wells Alternaria, Cladosporium, Peni- cillium and somewhat unusually Aspergillus, were isolated, but again no species names were provided. Few other taxa were detected in the other studies to which could be ascribed a particular deleterious character.

The lists of taxa reported in other investigations vary from study to study. West (1986) demonstrated that the fungi isolated from potable water were dematiaceous $(63 \%)$ and more specifically Cladosporium (27\%), Phoma (9\%), Alternaria and Exophiala (each 7\%). Arvanitidou et al. (1999) indicated the prevailing genera were Penicillium, Aspergillus and Candida. Common allergenic Aspergillus were encountered rarely, and Acremonium, Exophiala, Penicillium and Phialophora dominated. Some were encountered throughout the drinking water system and constituted a residual flora. In addition, soft deposits in pipelines were key sites for fungi (Zacheus et al., 2001). However, what other effects are possible?

A dramatic increase in the numbers of invasive diseases due to filamentous fungi (ff) has occurred recently (Anaissie et al., 2003; Arvanitidou et al., 1999). Interestingly, the genotype of $A$. fumigatus from water was related to that of isolates from two patients (Warris, 2003) indicating that water was the source of infection. The increase is attributed to the large numbers of patients undergoing immunosuppressive therapies, chemotherapy, and organ and bone marrow transplants; AIDS patients are also at risk. Aspergillus is by far the most common and A. fumigatus accounts for $90 \%$ of cases (Sheppard et al., 2004). Fusarium and zygomycetes are common problems amongst the remainder. It is of course likely that at least some of these will be present in water supplies at some stage, and consequently pose a threat. Furthermore, Esch (2004) describes 236 unique fungal allergic extract products representing 45 genera and 73 species of fungi. All these are available to identify which fungi produce allergies, and a significant number have been reported from water.

Although not a health problem per se, many of the compounds produced by bacteria in relation to taste and odour are also produced by fungi. In addition, they produce their own battery of compounds with distinctive odours and tastes. Fungal isolates were capable of transforming 2,4,6-tricholorophenol to 2,4,6-trichloroanisol which causes taste and odour problems in distribution system. Canhoto and Magan (2003) suggested "electronic nose" technology to detect bad odours from fungi in potable water. Furthermore, a musty smell in the Parisian water system was attributed to fungi (Monteil et al., 1999). A survey indicated the occurrence of taste and odour problems which were attributed to actinomycetes or algae, but not fungi for which the reasons were not obvious (Kelley et al., 2003). However, there is even less if any information of the production of pigments from fungi in water. 
Bad tastes in water have been ascribed to microfungi for decades (Kelley et al., 2003). They have often been associated with pipe wall growth of microorganisms, i.e. biofilms. The organisms can be actinomycetes, cyanobacteria, and fungi. A wide range of compounds can participate apart from the well-known geosmin. Many of the genera of fungi isolated from water in the past can produce chemicals that have bad tastes. Counts of $10^{2}-10^{3} \mathrm{cfu} / 1$ were often obtained from consumer complaint samples which may be a critical level in this respect (in addition, see "Discussion").

Systematic studying of the fungi in drinking water distribution systems is beginning to increase, although it is usually undertaken in response to an isolated contamination problem. There have been only a few reports from distribution systems (ca. 15) from approximately 10 countries, and virtually none from developing countries (Kelley et al., 2003). A limited number of investigations (Hinzelin and Block, 1985; Nagy and Olson, 1982; Rosenzweig et al., 1986) demonstrate that fungi are present in a significant proportion of tap water samples but the range of species is extremely variable. A 12-month survey was performed in Germany on drinking water from 29 water supplies to assess the dissemination of "hygienically relevant" fungi (Göttlich et al., 2002). Importantly, a correlation with standard hygiene bacterial indicators was not found.

In the present study, Portuguese tap water was examined for the presence of mesophilic ff in relation to other bacteria and yeasts over a 16-month period as part of the European project on safer tap water. Importantly, many of the penicillia were identified to the species level.

\section{Materials and methods}

\section{Water sampling}

Samples of tap water (1 litre) were collected between March 2003 and July 2004 on a monthly basis (apart from June 2003) by the University of Minho, Braga, Portugal. Sterile sample bottles were dosed with $4.7 \%$ $(\mathrm{w} / \mathrm{v})$ sodium thiosulphate as a chlorine neutraliser. Taps were flushed for $5 \mathrm{~min}$ and the tap did not touch the bottle before and during sampling. The water was $\mathrm{pH} 5.5-6.0$ with free chlorine from 0.45 to $0.75 \mathrm{mg} / 1$.

\section{Microbiological sampling}

Filtering: Samples were filtered through sterile $0.45 \mu \mathrm{m}$ membrane $(47 \mathrm{~mm}$ diameter) cellulose nitrate filters (Millipore HAWG047S1). These were directly incubated on plates at $25^{\circ} \mathrm{C}$ for 1 week and examined daily. Four media were chosen: tap water agar (TWA), half-strength corn meal agar (CMA/2), neopeptoneglucose rose Bengal aureomycin (NGRBA) and oomycete selective medium (OSM). OSM was used for its capacity to isolate slower growing fungi. The non-ff counts on NGRBA can be considered as presumptive yeasts because of the antibacterial effects of the aureomycin antibiotic.

Swabbing: The inner surface of a tap was sampled. The swab was then rinsed in saline solution $(\mathrm{NaCl}, 0.9 \%$ $(w / v))$. A sample $(100 \mu l)$ was spread over the medium surface. Another sample $(1 \mathrm{ml})$ was incorporated into the molten medium at $45^{\circ} \mathrm{C}$, shaken and dispensed into Petri dishes. TWA, CMA/2, NGRBA and OSM were used and cultures were grown for 7 days at $25^{\circ} \mathrm{C}$.

Baiting: This method was designed for zoosporic fungi. Several $0.5 \mathrm{~cm}^{2}$ pieces of autoclaved snake skin (dialysis membrane, Pierce, USA) or cellophane were added to samples (11) in shake flasks and incubated for up to a week at $25^{\circ} \mathrm{C}$. Baits with presumptive fungi were plated onto OSM for 7 days. The compositions of all media used are given in Table 1. Most samples were plated out onto three agar plates per treatment, i.e. in triplicate.

\section{Enumeration and identification of filamentous fungi}

All cfu on agar plates were enumerated. Ff were transferred to malt extract agar (MEA). Fungi were identified on the basis of macroscopic and microscopic features at Micoteca da Universidade do Minho (Ellis, 1971; Raper and Fennell, 1965). Most penicillia were identified to species according to the procedures of Pitt (1979) and Pitt and Hocking (1997).

\section{Results}

Only few fungi and other microbes were isolated by the baiting and swabbing methods. There was an approximately 100 -fold reduction of total counts to fungal counts (Fig. 1). Three major peaks in non-ff cfu counts were observed: April/May 2003, September 2003 and May to July 2004. The high November 2003 to February $2004 \mathrm{ff}$ counts coincided with low bacterial and yeast (b/y) and presumptive yeast counts. Conversely, the low values between April 2003 and October 2003 coincided with high $\mathrm{b} / \mathrm{y}$ and presumptive yeast levels. However, a high ff value was observed on May 2004 together with high $\mathrm{b} / \mathrm{y}$ and presumptive yeast values. Odours were not detected from any of the samples.

The counts on TWA, CMA/2 and OSM (Fig. 2) were generally lower than those on NGRBA (see Fig. 1). An average of less than a single colony was usually determined. However, a high value was obtained for 
Table 1. Media employed in this investigation

\begin{tabular}{|c|c|}
\hline Components & Quantity \\
\hline \multicolumn{2}{|l|}{$T W A$ (tap water agar) } \\
\hline Agar & $15 \mathrm{~g}$ \\
\hline Tap water & $1000 \mathrm{ml}$ \\
\hline \multicolumn{2}{|l|}{$C M A / 2$ (corn meal agar half-strength) } \\
\hline Corn meal agar & $8.5 \mathrm{~g}$ \\
\hline Agar & $8.5 \mathrm{~g}$ \\
\hline Distilled water & $1000 \mathrm{ml}$ \\
\hline $\mathrm{pH}$ & $6.0 \pm 0.2$ \\
\hline \multicolumn{2}{|c|}{ NGRBA (neopeptone glucose rose Bengal aureomycin) } \\
\hline Neopeptone & $5 \mathrm{~g}$ \\
\hline Glucose & $10 \mathrm{~g}$ \\
\hline $0.67 \%(\mathrm{w} / \mathrm{v})$ aureomycin solution & $5.0 \mathrm{ml}$ \\
\hline $1 \%(\mathrm{w} / \mathrm{v})$ rose Bengal solution & $3.5 \mathrm{ml}$ \\
\hline Agar & $15 \mathrm{~g}$ \\
\hline Distilled water & $1000 \mathrm{ml}$ \\
\hline $\mathrm{pH}$ & $6.5 \pm 0.2$ \\
\hline \multicolumn{2}{|l|}{ OSM (oomycete selective medium) } \\
\hline Corn meal agar & $17 \mathrm{~g}$ \\
\hline Agar & $23 \mathrm{~g}$ \\
\hline Sucrose & $20 \mathrm{~g}$ \\
\hline $\mathrm{MgSO}_{4}$ & $10 \mathrm{mg}$ \\
\hline $\mathrm{CaCl}_{2}$ & $10 \mathrm{mg}$ \\
\hline $\mathrm{ZnCl}_{2}$ & $1 \mathrm{mg}$ \\
\hline $\mathrm{FeSO}_{4}$ & $0.02 \mathrm{mg}$ \\
\hline $\mathrm{CuSO}_{4}$ & $0.02 \mathrm{mg}$ \\
\hline $\mathrm{MoO}_{3}$ & $0.02 \mathrm{mg}$ \\
\hline Thiamine hydrochloride & $2 \mathrm{mg}$ \\
\hline $\begin{array}{l}\text { Benlate }^{\mathrm{a}} \text { (benomyl) stock suspension }(0.5 \mathrm{~g} \\
\text { Benlate in } 500 \mathrm{ml} \text { distilled water) }\end{array}$ & $25 \mathrm{ml}$ \\
\hline Distilled water & $975 \mathrm{ml}$ \\
\hline
\end{tabular}

After sterilising, the medium was stored in the dark and used within $36 \mathrm{~h}$. ${ }^{\mathrm{a}}$ Benlate was dissolved very well in a chloroform solution; it cannot be dissolved in chloroform.

$\begin{array}{ll}\text { Malt extract agar }(M E A) & \\ \text { Malt extract } & 20 \mathrm{~g} \\ \text { Peptone } & 1 \mathrm{~g} \\ \text { Glucose } & 20 \mathrm{~g} \\ \text { Agar } & 20 \mathrm{~g} \\ \text { Distilled water } & 1000 \mathrm{ml} \\ \text { pH } & 5.6 \pm 0.2\end{array}$

Agar technical (agar no. 3) - OXOID Ltd., Basingstoke, Hampshire, England.

Malt extract - OXOID Ltd., Basingstoke, Hampshire, England.

Corn meal agar - DIFCO Laboratories, Detroit, MI, USA.

Rose Bengal solution - Sigma CHEMICAL CO., USA.

Aureomycin (chlortetracycline) - BD Difco Antimicrobic Vial A, Becton, Dickinson and Company, Sparks, USA.

CMA/2 on May 2003 which corresponded to high b/y counts (Fig. 1). Two colonies on average were observed for OSM on February 2004. The distribution of the predominate taxa is provided in Fig. 3. There was a large increase in Penicillium sp. in May 2003 which reached a low level by August 2003. A large increase in $P$. expansum was observed in May 2004. An increase in P. brevicompactum was noted in April 2004. However, for this fungus low counts were detected throughout the sampling period. In contrast, there was a large peak in the numbers of Acremonium sp. between November 2003 and February 2004 to the near exclusion of other taxa. The surfaces of the baits tended to be completely covered with bacteria and yeasts which made counts impossible. Nevertheless, 20 isolates of $P$. brevicompactum were obtained from the cellophane bait of May 2004. Few fungi were isolated by swabbing. However, 4 $P$. expansum strains were isolated by pour plating on February 2004 using CMA/2 and similarly for $1 P$. glabrum on September 2003. P. brevicompactum and $P$. corylophilum were isolated by direct plating. The present study demonstrated that NGRBA provides the highest recovery of ff, most (313 out of 340) were observed by employing the filtering method (Table 2). Strains belonged to 8 genera, the most abundant being Acremonium and Penicillium which accounted for $79.4 \%$. The next were Phialophora, Cladosporium and Rhizopus stolonifer accounting for $10.6 \%$, Alternaria, Aspergillus and Chaetomium for $1.2 \%$. Fungi without conidiophores or unidentified accounted for $8.8 \%$. A total of 97 of 138 Penicillium were identified to species: $P$. brevicompactum (45), P.corylophilum (1), P. crustosum (1), P. expansum (46), P. glabrum (1), P. griseofulvum (1), P. raistrickii (1) and $P$. waksmanii (1).

\section{Discussion}

The main objective of this study was to determine whether Braga, Portugal tap water, as represented by the University of Minho supply, is a source of ff and our results affirm this hypothesis. It is impossible to say whether the data represent the in vivo situation, or whether it is due to the isolation and growth methods involved. The bacteria and yeast could have inhibited the ff by competition for nutrients, for example, or perhaps the ff inhibited the single celled microbes by toxin production. However, it demonstrates a reason why ff might be ignored in favour of bacteria. The longer growth time of ff may lead to their underestimation. The swabbing method did not reveal many organisms indicating that biofilm formation had not occurred on the interior of the tap.

A flux of counts throughout the months was observed. It is surprising that the ff are prevalent in the presumably colder winter months although this may depend on the relative growth rates. High ff counts on the media without antibiotics on May 2003 (CMA/2) and February 2004 (OSM) may indicate that antibiotic 


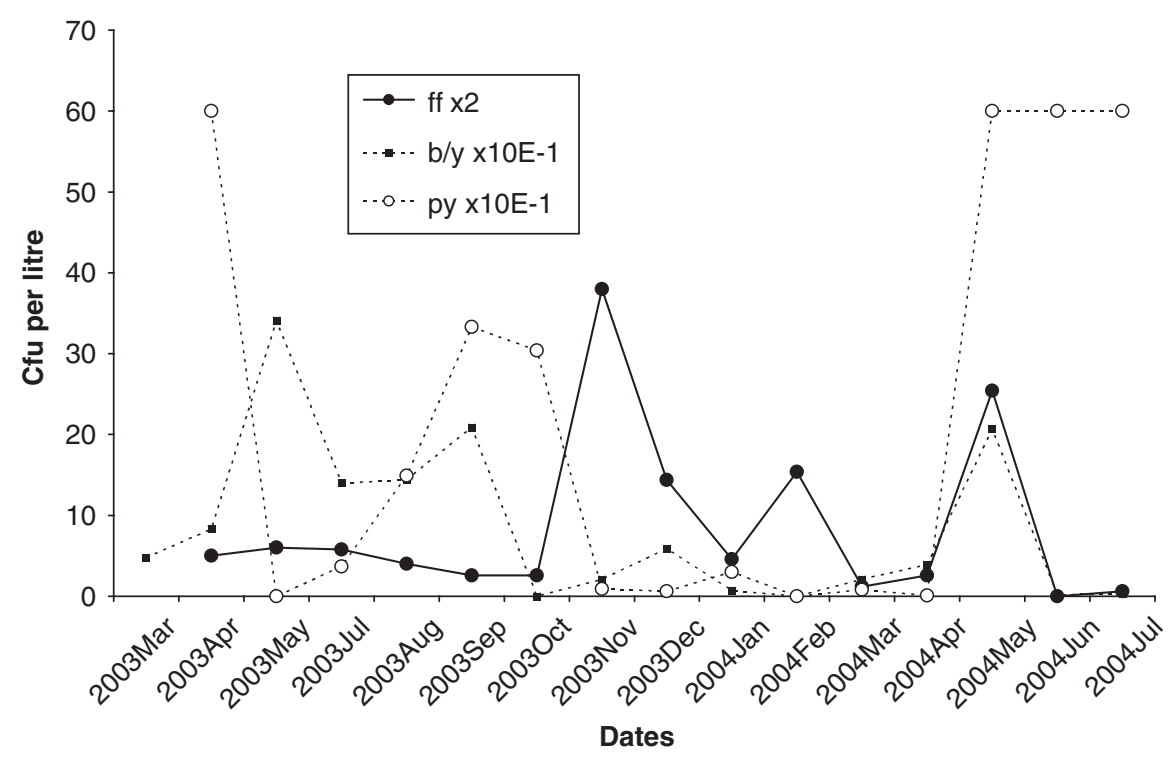

Fig. 1. Cfu of bacteria/yeast (b/y) on TWA, CMA/2, and OSM; presumptive yeast (py) on NGRBA; and filamentous fungi (ff) from NGRBA. N.B. The $\mathrm{b} / \mathrm{y}$ and py figures were multiplied by $10^{-1}$ and $\mathrm{ff}$ by $\times 2$ to facilitate comparisons between the data.

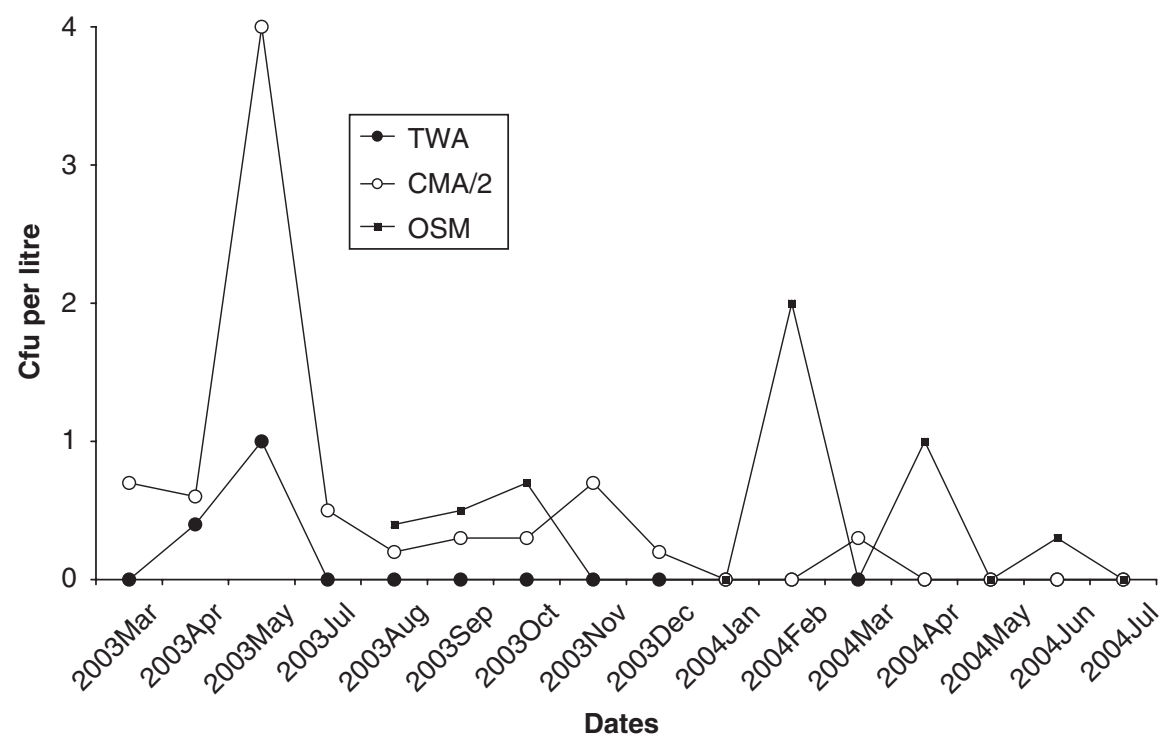

Fig. 2. Cfu of filamentous fungi on various media.

substances were produced by the fungi. The fungi were Penicillium sp. and $P$. expansum, and many are toxin and antibiotic producers. For example, $P$. expansum is well known to produce patulin. P. brevicompactum is suspected of producing patulin (Paterson, 2004) and does produce the immunosuppressive pharmaceutical mycophenolic acid.

As mentioned, cfu are misleading and will tend to underestimate the levels with respect to the fact that a colony from a single conidium would be the minimum requirement. It is more likely to be from many fungal structures in combination. So a clump of the fungus would create one colony and there might be more biomass than is indicated by cfu. Further, mycotoxins are likely to be produced externally to the fungal cells, which would tend to increase levels. Mycotoxins concentrations will tend to be low except in particular circumstances such as stored water, or dead ends in water pipes. Finally, increased levels of mycotoxins from deliberate addition cannot be ignored although is not strictly within the remit of the current paper. Therefore, it is at least useful to know what base line levels of fungi exist.

The distribution of the taxa throughout the time period is intriguing (Fig. 3). There appears to be quite distinct "seasons" for the taxa. This may relate to the 


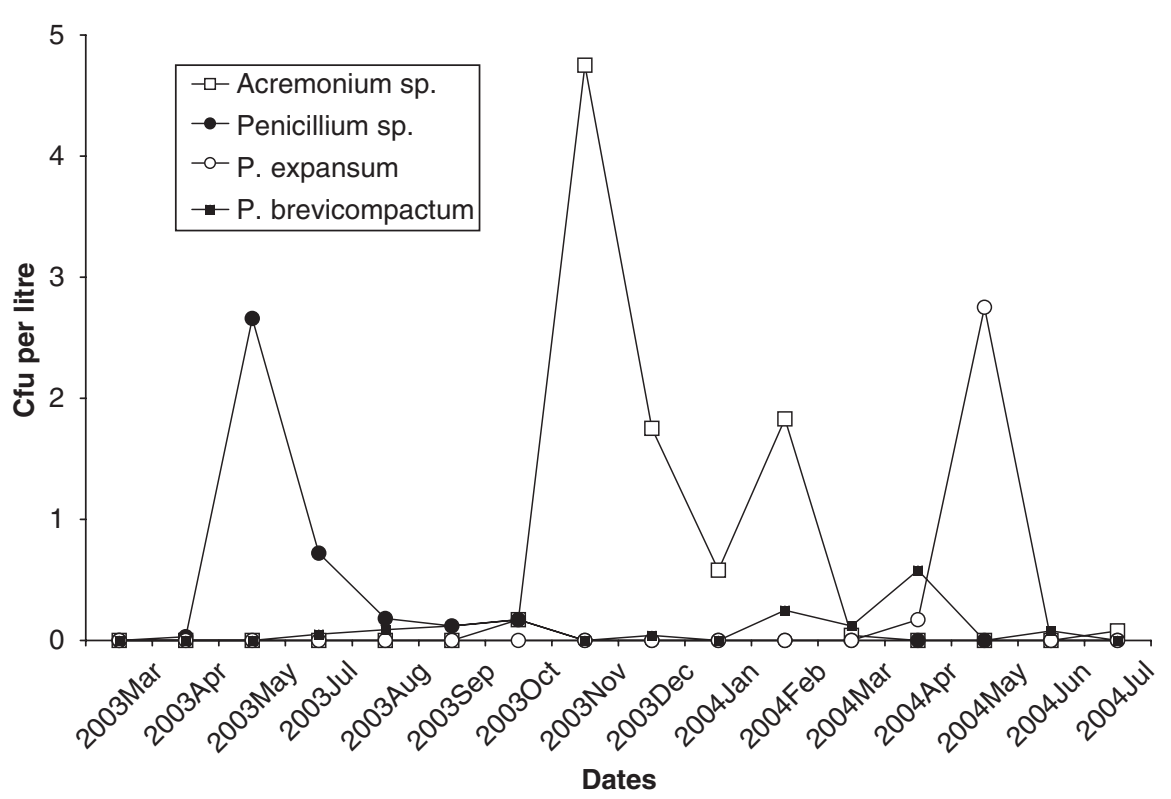

Fig. 3. Distribution of the key taxa throughout the sampling period. Penicillium sp. are all the unidentified and identified representatives apart from $P$. expansum and P. brevicompactum.

Table 2. Fungi identified in tap water by filtering, swabbing and baiting methods from March 2003 to July 2004

\begin{tabular}{lrr}
\hline Fungi & Number & $\%$ \\
\hline Acremonium & 132 & 38.82 \\
Alternaria & 1 & 0.29 \\
Aspergillus & 1 & 0.29 \\
Chaetomium & 2 & 0.59 \\
Cladosporium & 12 & 3.53 \\
Penicillium & 138 & 40.59 \\
Phialophora & 14 & 4.13 \\
Rhizopus stolonifer & 10 & 2.94 \\
Mycelia sterilia & 9 & 2.64 \\
Unidentified & 21 & 6.18 \\
Total & 340 & 100.00 \\
\hline
\end{tabular}

climatic conditions during these periods. Braga has hot summer months and temperate winter temperatures. Rainfall is high in winter.

The two most abundant genera found were Penicillium and Acremonium. Conidiation is adapted to spread via air because of hydrophobic conidia and water contamination may be unlikely on this basis. However, many other factors will be involved such as physical entrapment of the spores. Acremonium was associated with the colder weather according to the present results. This genus is known to produce octenol as a major component of odours (Kaminsky et al., 1980). A large number of $P$. expansum strains, which can be patulin producers, were isolated in May 2004. Patulin is a mycotoxin that has statutory or action levels in many countries. The compound is a bacterial quorum sensing inhibitor (Rasmussen et al., 2005). This species can also produce geosmin which is associated with earthy smells associated with problem waters. In fact, many penicillia produce geosmin and patulin (Paterson, 2004).

In terms of the known human pathogens, Aspergillus was not isolated frequently from the water and Fusarium sp. were undetected. Although the incubation temperature of $25^{\circ} \mathrm{C}$ was for mesophiles, the thermotolerant Aspergillus sp. may have overgrown other microorganisms if it had been at higher temperature. $R$. stolonifer was isolated once in late summer 2003. Zygomycetes are known to be a cause of disease in immunocompromised patients (Sheppard et al., 2004). The number of ff in the Braga water varied between 1 and $20 \mathrm{cfu} / 1$ but rarely exceeded $4 \mathrm{cfu} / 1$. This is in the same range as results ( $28 \mathrm{cfu} / \mathrm{l})$ presented by Kelley et al. (2003). Free chlorine levels in the Portuguese tap water reported here were particularly high $\left(0.45-0.75 \mathrm{mg}^{-1}\right)$. However, free chlorine levels of 2 and total chlorine concentrations of $10 \mathrm{mg} / \mathrm{l}$ have been reported (Kelley et al., 2003). Nagy and Olson (1982) found mean ff counts of $1.8 \times 10^{2} \mathrm{cfu} / 1$ in chlorinated surface waters. In Norway, the abundance of fungi in surface and treated water with little or no chlorine varied between $9.0 \times 10^{2}$ and $1.9 \times 10^{4} \mathrm{cfu} / 1$. Ff counts in distribution system seldom reached double figures per litre in the review by Kelley et al. (2003) which is similar to the situation in the present study. Average counts of $3.7 \times 10^{2} \mathrm{cfu} / 1$ were reported for $\mathrm{ff}$ in tap water from hospitals and communities in Greece in a more relevant comparison to the tap water here. Higher 
levels were detected by Rosenzweig and Pipes (1988a, b). A water with fungal level densities of $10^{3} \mathrm{cfu} / 1$ and higher can be problematic in terms of taste and odour (Åkerstrand, 1987). Our results do not represent a problem in this respect. The levels in previous studies ranged from 0 to $3.8 \times 10^{3} \mathrm{cfu} / 1$ (Kelley et al., 2003) when all samples were considered and not just tap water which is probably an invalid comparison. The presence of Alternaria alternata, A. niger, and in five samples Cladosporium sp. from drinking water utilities showing taste and odour indicated that these fungi might be involved. These were also found in other locations (Kelley et al., 2003). Some of the taxa were present in swabs of pipes indicating that they may form parts of biofilms and contribute to tastes and odours in this manner.

There is little data as to the species involved in many studies as they were seldom identified to that level. In the review of Kelley et al. (2003), Alternaria alternata, A. niger, Cladosporium sp., Epiccocum nigrum and many Penicillium sp. were prevalent. P. brevicompactum was rather frequently detected and $P$. expansum considerably less so. However, none of these were detected from the two tap water sites, although Fusarium sp. were common together with an unnamed zygomycetes. Very few Aspergillus sp. were detected and including the thermophilic ones which are involved in human disease (i.e. largely $A$. fumigatus). Again, high incubation temperatures do not appear to have been employed in this study.

Unsurprisingly, Penicillium has been shown to be common in previous studies (Kelley et al., 2003). However, it is moderately unexpected that especially Aspergillus was not more common in water systems. Incubation temperatures are crucial here, and it is essential to incubate cultures at elevated temperatures of $30^{\circ} \mathrm{C}$ to isolate fungi such as $A$. fumigatus. Other human pathogens may also require higher incubation temperatures (at least body temperatures). Future work in this laboratory will examine which fungi grow at these temperatures.

A rather wide range of other genera was identified in previous studies perhaps reflecting the variety of methods used and the unique environments studied. However, many taxa were isolated from the US distribution systems (Kelley et al., 2003) where methods were more standardised. Fusaria were well represented, and aspergilli less so. Many of the fungi were potential toxin producers. Water utilities appear to have little expertise with these organisms largely because they have not been implicated directly in health or quality problems of water in the past. Information on the (a) treatment, (b) disinfectant regimes, (c) growth of fungi, and (d) ability to produce secondary metabolites including mycotoxins are scarce. In the survey undertaken by Kelley et al. (2003), treatment significantly reduced the numbers of fungi including yeasts in the distribution system. It is assumed that fungi scavenge nutrient from the environment to support growth in oligotrophic (very low nutrient) situations such as water. They could colonise biofilms on pipe material after a significant period of exposure, and may be secondary colonisers once biofilm has established.

Most work on mycotoxin production in dilute systems has been summarised by Kelley et al. (2003) and results indicate that mycotoxins can be produced in submerged growth in water. Also, aflatoxins and other compounds were detected in a water tank where other microorganisms were present. Much more work is required in this regard to mycotoxins in biofilms where indeed the contribution of fungi is generally not appreciated. As mentioned, normally the levels of mycotoxins would be low. However, fungi from water could grow on foodstuff or infect people and start producing significant amounts of toxin.

Åkerstrand (1987) reported that $10^{3} \mathrm{cfu} / 1$ could translate to enough biomass to cause odours especially if one realises that this probably represents more than $10^{3}$ (see above). However, small concentrations of odour chemical could perhaps be detected by humans as the nose is a sensitive organ. However, more work is required. Growth of actinomycetes in water is known and they can produce geosmin. It is worth pointing out that odour was not detected in the present study.

Variation in taxa observed is often attributed to factors such as raw water source, water temperature patterns, treatment patterns and maintenance of distribution systems. Additionally, it was reported that fungi can pass through treatment processes by means of leaks in the system, or from air in contact with water stored in distribution system reservoirs and survive disinfection of water with chlorine (Niemi et al., 1982). It is of course impossible to make generalised conclusions about fungi from water systems on the basis of this study. It will depend on the system involved in the particular building where samples were taken. The sources of contamination via air and soil will be as diverse as the infrastructure of the water distribution system investigated.

\section{Acknowledgements}

This work has been undertaken as part of a research project which is supported by the European Union within the Fifth Framework Programme, "Energy, environment and sustainable development programme", No. EVK1-2002-00108. The authors are solely responsible for the work, it does not represent the opinion of the Community and the Community is not responsible for any use that might be made of data appearing herein. R.R.M. Paterson was supported by the Grant FRH/ 
BPD/14923/2004 from Fundação para a Ciência e Tecnologia (FCT), Portugal.

\section{References}

Åkerstrand, K., 1987. Dricksvattenkvaliteit och hälsa. Statens Livsmedelsverk, Report 18.2.1987, Dnr 1735/84.

Anaissie, E.J., Stratton, S.L., Dignani, M.C., Lee, C., Summerbell, R.C., Rex, J.H., Monson, T.P., Walsh, T.J., 2003. Pathogenic molds (including Aspergillus species) in hospital water distribution systems: a 3-year prospective study and clinical implications for patients with hematologic malignancies. Blood 101, 2542-2546.

Arvanitidou, M., Kanellou, K., Constantinides, T.C., Katsouyannopoulos, V., 1999. The occurrence of fungi in hospital and community potable waters. Lett. Appl. Microbiol. 29, 81-84.

Canhoto, O.F., Magan, N., 2003. Potential for detection of microorganisms and heavy metals in potable water using electronic nose technology. Biosens. Bioelectron. 18, 751-754.

CAST, 2003. Mycotoxins: Risks in Plant, Animal, and Human Systems. Council for Agricultural Science and Technology, Ames, IA.

Ellis, M.B., 1971. Dematiaceous Hyphomycetes. Cab International, Wallingford

Esch, R.E., 2004. Manufacturing and standardizing fungal allergen products. J. Allergy Clin. Immunol. 113, 210-215.

Göttlich, E., van der Lubbe, W., Lange, B., Fiedler, S., Melchert, I., Reifenrath, M., Flemming, H.-C., de Hoog, S., 2002. Fungal flora in groundwater-derived public drinking water. Int. J. Hyg. Environ. Health 205, 269-279.

Hawksworth, D.L., 2004. Fungal diversity and its implications for genetic resource collections. Stud. Mycol. 50, 9-18.

Hinzelin, F., Block, J.C., 1985. Yeasts and filamentous fungi in drinking water. Environ. Technol. Lett. 6, 101-106.

Kaminsky, E., Stawicki, S.T., Wasowicz, E., Tsubaki, K., 1980. Volatile odour substances produces by microflora. Die Nahrung 24, 103-113.

Kelley, J., Kinsey, G., Paterson, R., Brayford, D., Pitchers, R., Rossmore, H., 2003. Identification and Control of Fungi in Distribution Systems. Awwa Research Foundation and American Water Works Association, Denver.

Monteil, A., Rigal, S., Welte, B., 1999. Study of the origin of musty taste in the drinking water supply. Water Sci. Technol. 40, 171-177.

Nagy, L.A., Olson, B.H., 1982. The occurrence of filamentous fungi in drinking water distribution systems. Can. J. Microbiol. 28, 667-671.

Niemi, R.M., Knuth, S., Lundstrom, K., 1982. Actinomycetes and fungi in surface waters and in potable water. Appl. Environ. Microbiol. 43, 378-388.
Paterson, R.R.M., 2004. The isoepoxydon dehydrogenase gene of patulin biosynthesis in cultures and secondary metabolites as candidate PCR inhibitors. Mycol. Res. 108, 1431-1437.

Paterson, R.R.M., Kelley, J., Gallagher, M., 1997. Natural occurrence of aflatoxins and Aspergillus flavus (LINK) in water. Lett. Appl. Microbiol. 25, 435-436.

Paterson, R.R.M., Lima, N., 2005. Fungi in drinking water. In: Lehr, J.H., Keeley, J. (Eds.), Water Encyclopedia: The Water Quality and Resource Development. Wiley, New York.

Pitt, J.I., 1979. The Genus Penicillium and its Teleomorphic States Eupenicillium and Talatomyces. Academic Press, London.

Pitt, J.I., Hocking, A.D., 1997. Fungi in Food Spoilage. Academic Press, London.

Raper, K.B., Fennell, D.I., 1965. The Genus Aspergillus. Williams \& Wilkins, Baltimore.

Rasmussen, T.B., Skindersoe, M.E., Bjarnsholt, T., Phipps, R.K., Christensen, K.B., Jensen, P.O., Anderson, J.B., Koch, B., Larsen, T.O., Hentzer, M., Eberl, L., Hoiby, N., Givskov, M., 2005. Identity and effects of quorum-sensing inhibitors produced by Penicillium species. Microbiol. 151, 1325-1340.

Rosenzweig, W.D., Pipes, W.O., 1988a. Fungi from potable water: interaction with chlorine and engineering effects. Water Sci. Technol. 20, 153-159.

Rosenzweig, W.D., Pipes, W.O., 1988b. Presence of fungi in drinking water. In: Larson, R.A. (Ed.), Biohazards of Drinking Water Treatment. Proceedings of the 194th American Chemical Society National Meeting. American Chemical Society, Washington, DC.

Rosenzweig, W.D., Minnigh, H.A., Pipes, W.O., 1986. Fungi in potable water distribution systems. J. AWWA 78, $53-55$.

Sheppard, D.C., Ibrahim, A.S., Edwards Jr., J.E., 2004. Human mycosis: the role of molecular biology. In: Tkacz, J.S., Lange, L. (Eds.), Advances in Fungal Biotechnology for Industry, Agriculture and Medicine. Kluwer Academic/ Plenum Publishers, New York, pp. 361-384.

Warris, A., 2003. Hospital water-is it safe? Invasive aspergillosis and hospital water. Abstract. In: 13th European Congress of Clinical Microbiology and Infectious Diseases, 13 May, Glasgow.

West, P.R., 1986. Isolation rates and characterization of fungi in drinking water distribution systems. In: Proceedings of the Water Quality Technology Conference. AWWA, Denver, CO.

Zacheus, O.M., Lehtola, M.J., Korhonen, L.K., Martikainen, P.J., 2001. Soft deposits, the key site for microbial growth in drinking water distribution networks. Water Res. 35, 1757-1765. 